\title{
Home supported discharge was as effective and safe as standard hospital admission in patients with chronic obstructive pulmonary disease
}

\author{
Skwarska E, Cohen G, Skwarski KM, et al. Randomised controlled trial of supported discharge in patients with \\ exacerbations of chronic obstructive pulmonary disease. Thorax 2000 Nov;55:907-12.
}

\section{QUESTION: Is immediate or next day home supported discharge as effective and safe as standard hospital admission in patients presenting to hospital with an exacerbation of chronic obstructive pulmonary disease (COPD)?}

\section{Design}

Randomised \{allocation concealed\}*, unblinded, controlled trial with 8 weeks of follow up.

\section{Setting}

A hospital in Edinburgh, UK.

\section{Patients}

184 patients (mean age $69 \mathrm{y}, 53 \%$ women) who presented to hospital on a weekday with an exacerbation of COPD. Exclusion criteria were an impaired level of consciousness, acute confusion, acute changes on radiography, an arterial $\mathrm{pH}<7.35$, or a serious medical or social reason for admission. Follow up was $93 \%$.

\section{Intervention}

122 patients were allocated to home support and were discharged immediately or the next day with an appropriate treatment package (antibiotics, corticosteroids, nebulised bronchodilators, and, if necessary, home oxygen). These patients had a home visit by a respiratory nurse the day after discharge and every 2-3 days thereafter until recovery, at which time they were discharged from follow up. Nurses reviewed patient progress weekly with the consultant. Specialist advice was available daily and changes in prescription could be obtained in consultation with the patient's general practitioner (GP). 62 patients were allocated to hospital admission with standard care in the respiratory medicine unit.

\section{Main outcome measures}

Time to discharge, readmission rate, respiratory function tests, additional care by GPs or other carers, quality of life, and estimated healthcare costs.

\section{Main results}

The median time to discharge was 7 days for the home supported group and 5 days for the admitted group $(\mathrm{p}<0.01)$. At 8 weeks, no differences existed between the home supported and admitted groups for the rate of readmission $(25 \% v 34 \%)$, respiratory function, attendance by GPs and carers, or quality of life. The estimated mean total health service cost was $£ 877$ per patient for the home supported group and $£ 1753$ per patient for the admitted group.

\section{Conclusion}

Home supported discharge was as effective and safe as standard hospital admission for patients referred to hospital with an exacerbation of chronic obstructive pulmonary disease.

*Information provided by author.

COMMENTARY — continued from previous page

programmes. The findings showed that respiratory nursing expertise is required in early discharge home based care to assess patients and to access consultation. In both studies, 1 respiratory nurse delivered the home based service; however, community practice models commonly involve a group of general home care nurses. Therefore, the ability to widely implement such a strategy may be limited. Further research comparing the effectiveness of specialist nursing care to the more common practice model involving a group of general home care nurses would be beneficial to determine the best care delivery models for this patient population.

Another important aspect of the intervention was the availability of specialist respiratory medical care for consultation with the home based nurse. Typically, specialist medical consultation for home based care is limited and more accessible to hospital based services. This specialist medical consultation support may have been an important aspect of the intervention that supported the effectiveness of home based care. Those who are interested in generalising these findings to home based early discharge services in their communities need to acknowledge that both specialist nursing care and specialist medical consultation are important components of early discharge care.

\section{Della Roberts, RN, MScN Coordinator, Palliative Care Delta Health Services Delta Hospital Delta, British Columbia, Canada}

1 Smith B, Appleton S, Adams R, et al. Home care by outreach nursing for chronic obstructive pulmonary disease. Cochrane Database Syst Rev 2000;(2):CD00094 (latest version 17 Oct 1999)

2 Siafakas NM, Vermeire P, Pride NB, et al. Optimal assessment and management of chronic obstructive pulmonary disease (COPD). The European Respiratory Society Task Force. Eur Respir J 1995;8:1398-420.

3 Standards for the diagnosis and care of patients with chronic obstructive pulmonary disease. American Thoracic Society. Am J Respir Crit Care Med 1995:152:S77-121.

4 BTS guidelines for the management of chronic obstructive pulmonary disease: the COPD Guidelines Group of the Standards of Care Committee of the BTS. Thorax 1997:52:S1-28. 